\title{
Mechanistic aspects of the DNA junction-resolving enzyme T7 endonuclease I
}

Jia Liu, Anne-Cécile Déclais and David M.J. Lilley

\section{SUPPLEMENTARY FIGURES}

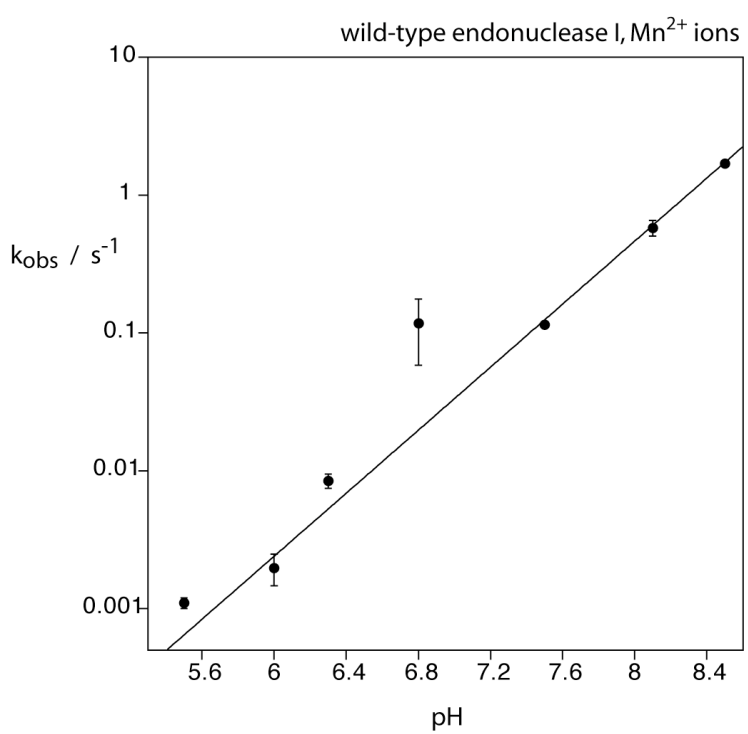

Figure S1. The $\mathrm{pH}$ dependence of the rate of cleavage of junction 3 by wild-type endonuclease I in the presence of $\mathrm{Mn}^{2+}$ ions. The rate of hydrolysis of the $\mathrm{h}$ strand of junction 3 by endonuclease I was measured in triplicate as a function of buffer $\mathrm{pH}$ in the presence of $10 \mathrm{mM} \mathrm{Mn}^{2+}$ ions. The rate has been plotted on a logarithmic scale as a function of $\mathrm{pH}$, and the data fitted to equation (2). The best fit gave a value of $n=1.0$ proton transfers required for formation of the active form of the enzyme. Error bars are standard errors.

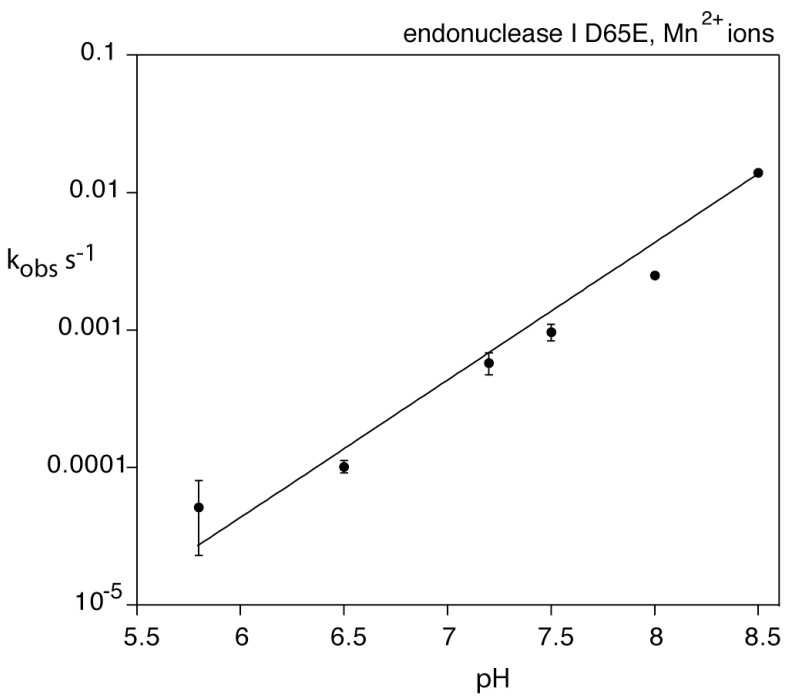

Figure S2. The $\mathrm{pH}$ dependence of the rate of cleavage of junction 3 by endonuclease I E65D in the presence of $\mathrm{Mn}^{2+}$ ions. The rate of hydrolysis of the $\mathrm{h}$ strand of junction 3 by endonuclease I was measured in triplicate as a function of buffer $\mathrm{pH}$ in the presence of $10 \mathrm{mM} \mathrm{Mn}^{2+}$ ions. The rate has been plotted on a logarithmic scale as a function of $\mathrm{pH}$, and the data fitted to equation (2). The best fit gave a value of $n=0.9$ proton transfers required for formation of the active form of the enzyme. Error bars are standard errors. 